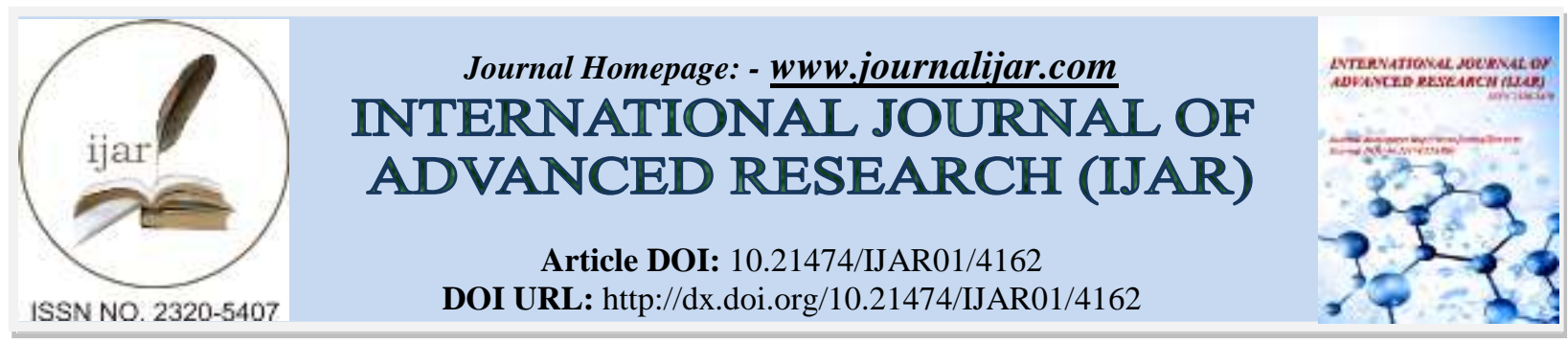

RESEARCH ARTICLE

\title{
PREVALENCE OF ORAL MUCOSAL LESIONS IN PEDIATRIC PATIENTS IN KASHMIR VALLEY.
}

\author{
Dr Mohammad Shafi Dar ${ }^{1}$, Dr Meena Syed ${ }^{2}$ and Dr Shazya Gul ${ }^{3}$ \\ 1. M.D.S , Dept. of Oral \& Maxillofacial Pathology \& Microbiology (BBDCODS). \\ 2. M.D.S , Dept. of Pediatric \& Preventive Dentistry. \\ 3. M.D. Post graduate Dept. of Anatomy, Govt. Medical College Jammu
}

\section{Manuscript Info}

Manuscript History

Received: 14 March 2017

Final Accepted: 08 April 2017

Published: May 2017

Key words:-

oral mucosal lesions, pediatric population, Kashmir valley, traumatic ulcers.

\section{Abstract}

Oral mucosal lesions are a broad range of different alterations located in the oral cavity. Most of the studies which describe the prevalence of oral mucosal lesions have been carried out mainly in an adult population. Therefore, in the literature available, there are few reports about oral mucosal lesions and alterations of the normal oral mucosa in pediatric population. A descriptive observational cross-sectional study was conducted, with non-probability sampling for convenience, with a sample of 110 patients and a level of confidence of $95 \%$. We estimated only 51 children which fitted our inclusive criteria. In 51 patients a prevalence of $37.2 \%$ of oral mucosal lesions was observed. The more prevalent lesions were minor aphthous ulcers $(21.5 \%)$, irritation fibroma $(15.7 \%)$, traumatic ulcer $(15.7 \%)$, traumatic erosion (10.2\%), impetigo (10.2\%), pigmented lesions, recurrent herpes labialis, recurrent intraoral herpes, mucocele, and ranula (5.2 \% each). The most frequent location observed in oral mucosal lesions, was labial mucosa $(25.0$ $\%)$, followed by vermilion border $(15.0 \%)$, buccal mucosa $(15.0 \%)$, labial commissures $(10.0 \%)$, buccal groove $(5.0 \%)$ etc. in conclusion, even though most of the oral mucosal lesions evaluated in this study can be diagnosed in a purely clinical way; there are some oral mucosal lesions that need confirmation through an anatomo-pathological study.

Copy Right, IJAR, 2016,. All rights reserved.

\section{Introduction:-}

Oral mucosal lesions located in the soft tissues of the oral cavity are a broad group of alterations, recognizable by their etiology, clinical characteristics, prognosis, and dissimilar treatments.

The fundamental to obtain a diagnosis of oral conditions and lesions is the clinical examination, which is why, it must be correct, thorough, and systematic. The proper examination of oral soft tissues in pediatric patients involves knowledge of normal size, shape, color, and texture of the structures that comprises it. The correct exploration of the oral mucosa can provide important tools in diagnosing developmental, neoplastic, infectious, or inflammatory alterations (Espinoza et al., 2003). 
The lesions in oral mucosa in children can present as ulcers, vesicles, macules, changes in color, texture, size," consistency and configuration of the oral anatomy (Donoso et al., 2013).

In kashmir, there are hardly any studies about oral mucosal lesions, neither in adult or pediatric populations. On the other hand, it is important to organize and standardize the criteria of examination for the various medical procedures in oral mucosa.

Several studies in different geographic locations have reported prevalence in oral mucosal lesions. In a study conducted in Argentina by Muniz et al., in 1981, for a total sample of 75 healthy pediatric male patients, ages 6 to 13 , 46 patients presented oral mucosal lesions, with a prevalence of $61.3 \%$. The most common lesions were angular cheilitis $(14.7 \%)$, followed by herpes labialis (10.7\%), impetigo $(9.3 \%)$, geographic tongue, recurrent aphthous ulcer, and verruca vulgaris (2.7\%) (Muñiz et al., 1981).

In a study carried out in South Africa by Arendorf et al. (1996), with a sample of 1051 patients, a $32.90 \%$ prevalence of oral mucosal lesions was observed. The most prevalent was the recurrent aphthous ulcer $(10.87 \%)$, followed by herpes labialis $(5.2 \%)$, angular cheilitis $(3.54 \%)$, geographic tongue $(2.95 \%)$, depapillated tongue $(2.6$ $\%)$, ankyloglossia, traumatic ulcer $(1.41 \%)$, mucocele $(1.18 \%)$ and impetigo (0.94\%) (Arendorf et al.).

In Mexico, Espinoza-Zapata (2006) conducted a study with a sample of 1165 patients between 1 and 16 years old. The prevalence of oral mucosal lesions was $7.4 \%$. The most frequent lesions were: fibrous hyperplasia $(3.18 \%)$, oral candidiasis $(1.89 \%)$, and ulcerative lesions (1.2\%) (Espinoza-Zapata et al.).

\section{Material and Method:-}

An observational, descriptive study was conducted. Non-probability sampling was used for convenience depending on scheduling and availability of the patients from the Pediatric Dentistry Clinic in kashmir. A sample of 110 patients from a population of 340 patients treated at that clinic in the year 2015, with a $95 \%$ level of confidence, 5 $\%$ margin of error, and an estimated of $30 \%$ of the pediatric patients with oral mucosal lesions. The sample was distributed into two groups: healthy patients and patients with systemic diseases.

The inclusion criteria were patients from 3 years old to 13 years old, both genders.

The sample was examined between July and December in 2015. Before this study was carried out on the clinical trial; the patients and their proxies signed an informed consent and assent.

In this study, the instrument used for measuring was the clinical record, based on the clinical exam of the oral mucosa applied by the World Health Organization described in the study "Guide to epidemiology and diagnosis of oral mucosal diseases and conditions" (Espinoza et al.) and in "Pediatric Oral Medicine" a guide of pediatric oral medicine (Witman et al., 2003), where the general data about children was registered by illnesses, type, and location of the lesion. This was carried out through direct observation without using complementary exams, which is why the diagnosis was based on the clinical exam. In case of finding any oral mucosal lesion, a photographic register of the lesion was taken.

The results obtained in the clinical records were processed using Microsoft Office Excel 2011 worksheet, where a descriptive statistic was made, doing statistical process of data.

\section{Results:-}

Fifty one pediatric patients were examined in the pediatric dentistry clinic in the Pediatric Dentistry Clinic in kashmir from July to December 2015, where all of the patients studied fitted the inclusion criteria In this group of 51 patients, $24(47.05 \%)$ were men and $27(52.9 \%)$ were female. The age group of the patients was from 4 to 13 years of age, with a median of 8 , and a mean of 8.7 years old.

Of the entirety of the sample, 19 patients $(37.2 \%)$ were diagnosed with at least one oral mucosal lesion during the exam. The frequency percentages of oral mucosal lesion in men and female were $36.2 \%$ in the former and $38.9 \%$ in the latter. Of these, only one patient had two lesions simultaneously (5.2\%). 
In Table I, the diagnosis of the 20 oral mucosal lesions in 19 patients can be appreciated. The more prevalent lesions were minor aphthous ulcers $(21.5 \%)$, irritation fibroma $(15.7 \%)$, traumatic ulcer $(15.7 \%)$, traumatic erosion $(10.2 \%)$, impetigo $(10.2 \%)$, pigmented lesions, recurrent herpes labialis, recurrent intraoral herpes, mucocele, and ranula $(5.2 \%$ each).

Respecting the anatomical location of the oral mucosal lesions, 5 were located on labial mucosa, 3 on the vermillion border, 3 on buccal mucosa, 2 on labial commissures, 1 on gingiva, 1 on the floor of the mouth, 1 on the buccal groove, 1 on dorsum of the tongue, 1 on apex of the tongue, 1 attached mucosa, and 1 on the hard palate, (Table II).

Table I:- Oral mucosal lesions presented in 19 patients. (1 patient presented 2 simultaneous diagnosis).

\begin{tabular}{|c|c|c|}
\hline Type of lesion & Number of lesions found & \%age \\
\hline Minor aphthous ulcers & 4 & $21.5 \%$ \\
\hline Irritation fibroma & 3 & $15.7 \%$ \\
\hline Traumatic ulcer & 3 & $15.7 \%$ \\
\hline Traumatic erosion & 2 & $10.5 \%$ \\
\hline Impetigo & 2 & $10.5 \%$ \\
\hline Pigmented lesions & 1 & $5.2 \%$ \\
\hline Recurrent herpes labialis & 1 & $5.2 \%$ \\
\hline Recurrent intraoral herpes & 1 & $5.2 \%$ \\
\hline Mucocele & 1 & $5.2 \%$ \\
\hline Ranula & 1 & \\
\hline Total & $\mathbf{1 9}$ & $5.2 \%$ \\
\hline
\end{tabular}

Table II;- Frequency of oral mucosal lesions distributed by anatomical location.

\begin{tabular}{|c|c|c|}
\hline Anatomical location & Frequency & $\begin{array}{c}\text { Prevalence of } \\
\text { lesions }\end{array}$ \\
\hline Labial mucosa & 5 & $25.0 \%$ \\
\hline Vermilion margin & 3 & $15.0 \%$ \\
\hline Oral mucosa & 3 & $15.0 \%$ \\
\hline Labial commissures & 2 & $10.0 \%$ \\
\hline Oral groove & 1 & $5.0 \%$ \\
\hline Gingiva & 1 & $5.0 \%$ \\
\hline Floor of the oral cavity & 1 & $5.0 \%$ \\
\hline Dorsum of tongue & 1 & $5.0 \%$ \\
\hline Apex of tongue & 1 & $5.0 \%$ \\
\hline Attached mucosa & 1 & $5.0 \%$ \\
\hline Hard palate & 1 & $\mathbf{1 0 0 \%}$ \\
\hline Total & $\mathbf{2 0}$ & \\
\hline
\end{tabular}

\section{Discussion:-}

The prevalence of oral mucosal lesions in this study was of $37.2 \%$ of the studied pediatric population. In the revised studies, this percentage varies from a $4.1 \%$ (Arendorf et al.) to a $78.4 \%$ (Espinoza-Zapata et al.). Even though the demographic characteristics of the studied population are different, the percentage of the lesions found in this study is very similar to the prevalence found in Argentina by Crivelli et al. (1988) being this one a $39.04 \%$; and also very similar to the one in Spain by García-Pola et al. (2002) which was $38.94 \%$.

The most prevalent pathologies were minor aphthous ulcer $(21.5 \%)$, irritation fibroma $(15.7 \%)$, traumatic ulcer $(15.7 \%)$, traumatic erosion $(10.5 \%)$, impetigo $(10.5 \%)$, pigmented lesions $(5.2 \%)$, herpes labialis $(5.2 \%)$, intraoral herpes $(5.2 \%)$, mucocele $(5.2 \%)$, ranula $(5.2 \%)$,

The most frequent location observed in oral mucosal lesions, was labial mucosa $(25.0 \%)$, followed by vermilion border $(15.0 \%)$, buccal mucosa $(15.0 \%)$, labial commissures $(10.0 \%)$, buccal groove $(5.0 \%)$, gingiva $(5.0 \%)$, floor of the mouth $(5.0 \%)$, apex of the tongue $(5.0 \%)$ dorsum of the tongue $(5.0 \%)$, attached mucosa $(5.0 \%)$, 
tonsillar pillars $(5.0 \%)$, hard palate $(5.0 \%)$. The anatomical location is similar to the one observed by Shulman (2005) with $30.7 \%$ on lips, and the one by Hussein \& Noori (2014) with a $37.4 \%$ on lips.

This study shows a tendency of frequent diagnoses of oral mucosal lesions that could be found in the Chilean population. The diagnosis of these oral mucosal lesions is a challenge for the dentist because of its varied clinical expression, which is why, early and adequate diagnosis, allows the application of accurate therapeutic proposals. It is important to continue this line of investigation in other pediatric populations in Chile and extending the sample size.

\section{Conclusions:-}

This study describes the frequency of oral mucosal lesions found in 19 patients out of 51 examined in the Pediatric Dentistry Clinic in Kashmir in 2015 from July to December. The prevalence of oral mucosal lesions was $37.2 \%$, similar to other epidemiological studies (Crivelli et al.; García-Pola et al.). The minor aphthous ulcer was the most prevalent oral mucosal lesion, followed by irritation fibroma, and traumatic ulcers. The most frequent anatomical location was labial mucosa $(25 \%)$. The most frequent age range was from 9 to 13 years old with 15 $\%$ of prevalence in oral mucosal lesions.Even though most of the oral mucosal lesions evaluated in this study can be diagnosed in a purely clinical way; there are some oral mucosal lesions that need confirmation through an anatomo-pathological study.

\section{References:-}

1. Bessa, C. F.; Santos, P. J.; Aguiar, M. C. \& do Carmo, M. A. Prevalence of oral mucosal alterations in children from 0 to 12 years old. J. Oral Pathol. Med., 33(1):17-22, 2004.

2. Arendorf, T. M. \& van der Ross, R. Oral soft tissue lesions in a black pre-school South African population. Community Dent. Oral Epidemiol., 24(4):296-7, 1996.

3. Crivelli, M. R.; Aguas, S.; Adler, I.; Quarracino, C. \& Bazerque, P. Influence of socioeconomic status on oral mucosa lesion prevalence in schoolchildren. Community Dent. Oral Epidemiol., 16(1):58-60, 1988.

4. Espinoza, I.; Rojas, R.; Aranda, W. \& Gamonal, J. Prevalence of oral mucosal lesions in elderly people in Santiago, Chile. J. Oral Pathol. Med., 32(10):571-5, 2003.

5. Cueto, A.; Martínez, R.; Niklander, S.; Deichler, J.; Barraza, A. \& Esguep, A. Prevalence of oral mucosal lesions in an elderly population in the city of Valparaiso, Chile. Gerodontology, 30(3):201-6, 2013.

6. Espinosa-Zapata, M.; Loza-Hernández, G. \& Mondragón-Balleste- ros, R. Prevalencia de lesiones de la mucosa bucal en pacien- tes pediátricos. Informe preliminar. Cir. Cir., 74(3):153-7, 2006.

7. García-Pola, M. J.; García-Martin, J. M. \& Gonzalez-Garcia M. Prevalence of oral lesions in the 6-year-old pediatric population of Oviedo (Spain). Med. Oral, 7(3):184-91, 2002.

8. Muñiz, B.; Crivelli, M. \& Paroni, H. Clinical study of oral soft tissue lesions in boys in a children's home. Rev. Asoc. Odontol. Argent., 69(7):405-8, 1981.

9. Pinto, A.; Haberland, C. M. \& Baker, S. Pediatric soft tissue oral lesions. Dent. Clin. North Am., 58(2):437-53, 2014.

10. Shulman, J. D. Prevalence of oral mucosal lesions in children and youths in the USA. Int. J. Paediatr. Dent., 15(2):89- 97, 2005.

11. Witman, P. M. \& Rogers III, R. S. Pediatric oral medicine. Dermatol. Clin., 21(1):157-70, 2003.

12. Hussein, S. A. \& Noori, A. J. Prevalence of oral mucosal changes among 6-13-year old children in Sulaimani city, Iraq. Sulaimani Dent. J., 1:5-9, 2014.

13. Jiménez-Palacios, C.; Ramírez, R.; Ortiz, V.; Virgüez, V. \& Benítez, A. Identificación de lesiones en los tejidos blan- dos de la cavidad bucal en adolescentes con privación de libertad en el odontopediátrico de carapa. Septiem- bre 2005- abril 2006 Venezuela. Acta Odontol. Venez., 47(2):327-33, 2009.

14. Jiménez-Palacios, C.; Kkilikan, R.; Ramírez, R.; Ortiz, V.; Virgüez, Y. \& Benítez, A. Levantamiento epidemiológico de lesiones patológicas en tejidos blandos de la cavidad bucal de los niños y adolescentes del centro odontopediátrico de Carapa, Parroquia Antímano, Ca- racas, Distrito Capital, Venezuela. Período MayoNo- viembre 2005. Acta Odontol. Venez., 45(4):540-5, 2007.

15. Kramer, I. R.; Pindborg, J. J.; Bezroukov, V. \& Infirri, J. S. Guide to epidemiology and diagnosis of oral mucosal diseases and conditions. World Health Organization. Community Dent. Oral Epidemiol., 8(1):1-26, 1980.

16. Köse, O.; Güven, G.; Özmen, I.; Akgün, Ö. M. \& Altun, C. The oral mucosal lesions in pre-school and school age Turkish children. J. Eur. Acad. Dermatol. Venereol., 27(1):e136-7, 2013.

17. Majorana, A.; Bardellini, E.; Flocchini, P.; Amadori, F.; Conti,G. \& Campus, G. Oral mucosal lesions in children from 0 to 12 years old: ten years' experience. Oral Surg. Oral Med. Oral Pathol. Oral Radiol. Endod., 110(1):e13-8, 2010. 